\title{
Rosas, Sabrina (2020) "Warmikunamanta Atipaq Sonqokuna: Mujeres de corazones valientes". Memoria, identidad y territorio indígena kolla en la ciudad de La Plata. Tesis para optar por el grado de Magíster en Historia y Memoria
}

\author{
Clara Inés Aprea \\ ineciaprea@gmail.com \\ Universidad Nacional de La Plata, Argentina
}

\author{
Citasugerida: Aprea, C. I. (2021). [Revisión de Tesis \\ "Warmikunamanta Atipaq Sonqokuna: Mujeres de corazones \\ valientes". Memoria, identidad y territorio indigena kolla en la \\ ciudad de La Plata por S. Rosas]. Aletheia, 12(23), e115. \\ https://doi.org/10.24215/18533701e115
}

Defensa de Tesis: $17 / 07 / 2020$

Directora: Dra. Susana E. Aguirre, Universidad Nacional de La Plata

Codirectora: Dra. María Marta Reca, Universidad Nacional de La Plata

Tanto en las políticas de memoria en Argentina como en la vasta producción académica en torno a las experiencias traumáticas de violencia estatal durante la última dictadura genocida, las memorias indígenas han sido tematizadas en forma marginal o subsidiaria respecto a otras categorías identitarias (Lenton, 2014). Estos silencios comienzan a romperse partir de la propia agencia indígena en los procesos de recuperación de las raíces ancestrales al calor de las luchas territoriales de las últimas décadas (Delrio, Lenton, Musanti, Nagy, Papazian y Pérez, 2010), y por un creciente campo de estudios en el que abreva la tesis de Sabrina Rosas "Warmikunamanta Atipaq Sonqokuna: Mujeres de corazones valientes". Memoria, identidad y territorio indigena kolla en la ciudad de La Plata.

Este trabajo de investigación indaga en la memoria de la Asociación Civil Warmikunamanta Atipak Sonqokuna desde un enfoque etnográfico, a partir de la voz de su referente, Illa Nan. Su nombre en quechua significa "camino de luz" y es una mujer indígena kolla conocida como figura pública en el ámbito platense como María Ochoa. La tesis se organiza en cuatro capítulos que desarrollan distintas entradas a los procesos de construcción identitaria indígena kolla a partir de las memorias sociales que se despliegan en el espacio 
urbano, sobre la base del análisis del testimonio, las prácticas performáticas y ceremoniales de Illa Nan y su activismo político-étnico.

El acercamiento a la Asociación y a su referente en el marco de un trabajo de extensión, comprende una experiencia conjunta en la que el encuentro de saberes tensiona las relaciones de poder entre quien investiga y su objeto. La presentación del tema y del problema de investigación en el primer capítulo explicita la vocación de interpelar los quehaceres de las ciencias sociales, a partir de la reflexión epistemológica y la interrogación sobre el propio rol de la investigadora. Desde la crítica a las formas extractivas de construcción del conocimiento científico, se plantea la búsqueda de un conocimiento dialógico que asigna a Illa Nan un rol de interlocutora antes que de informante, vínculo que hace posible un enfoque centrado en su enunciación y su acción político-étnica.

El trabajo de extensión y el comienzo de la investigación se desarrollaron a partir de una de las principales actividades de la Asociación Civil: el Taller Integral Indígena Wawa Wasi, un espacio educativo para niñxs hasta los 14 años que trabaja con las memorias ancestrales en la construcción de la identidad y que se desarrolla en el barrio Hipódromo de La Plata, sede de la comunidad Markawasi, una de las cuatro comunidades kollas de La Plata.

Un punto de partida central es la contextualización de los procesos de reconfiguración de las identidades indígenas, desde una perspectiva no esencialista y relacional, analizando la construcción de identidades étnicas como agenciamiento político del sujeto colonizado. Los procesos de construcción de memorias indígenas y los usos del pasado, atendiendo a la superposición de temporalidades o capas de memorias, se analizan desde este enfoque en el segundo capítulo. Se sostiene aquí que, en la articulación de memorias largas y cortas impulsada por la emergencia de movimientos sociales étnicos, la memoria se ancestraliza en tanto recurso político que otorga legitimidad al discurso y la acción indígena en el marco de las disputas presentes.

La memoria social recuperada por Illa Nan le atribuye un rol fundamental a las mujeres, asignando sentidos particulares a la diferencia sexual, que se expresan no sólo en su testimonio sino en las propias prácticas de la Asociación, cuyas actividades son sostenidas principalmente por mujeres. En el proceso de ancestralización de la memoria analizado por Sabrina Rosas tiene un lugar preeminente la "cultura del amor", la reconstrucción de un relato idealizado del pasado incaico, centrado en la vida en comunidad, que busca transmitirse a las nuevas generaciones. En esta cultura del amor, el rol materno-doméstico de las mujeres se presenta como equivalente al rol de cuidado y protección del territorio y de la naturaleza, en oposición a una violencia colonial que se identifica con atributos masculinos, blancos y occidentales.

La denominada "configuración de fronteras híbridas" expresa la relación entre memoria, espacio y territorio, no sólo en cuanto al espacio en términos materiales sino también en cuanto a la delimitación de un nosotros anclado en la sociedad incaica, desde un posicionamiento político que resignifica las formas de organización social en el pasado, antes que aferrarse al origen geográfico. En efecto, la tarea que se da a sí misma Illa Ñan es la de impulsar el "despertar", la identificación como indígenas de sus hermanos/as migrantes.

En el tercer capítulo las memorias son caracterizadas, en tanto elemento central en la recuperación de la identidad indígena kolla, en el marco de un esencialismo estratégico étnico y de género. La problematización del concepto de comunidad a partir de la interrogación sobre sus contornos y sus límites difusos, abre paso a la reflexión sobre la elaboración simbólica de la comunidad por parte de su líder, tensionando la usual asociación entre comunidad indígena y territorio ancestral. Wawa wasi, a través del conjunto de actividades que impulsa y lleva a cabo como espacio político, es identificado así como el territorio donde se configura la comunidad.

La construcción social del territorio indígena kolla en la ciudad es analizada con mayor profundidad en el cuarto capítulo. Si el espacio urbano, como realidad socialmente construida, expresa las relaciones sociales que lo disputan, la relación entre la Asociación y los distintos niveles del Estado se inscribe en el despliegue de acciones performáticas, protestas, prácticas rituales, ceremoniales y festividades, analizadas como vehículos de memoria e identidad. La falta de reconocimiento jurídico de la comunidad por parte de Estado replantea la cuestión de la delimitación comunitaria como problema político: la fundación de la Asociación en 2009 
expresó la búsqueda de alternativas para acceder a herramientas legales que habiliten la gestión de recursos y el acceso a derechos indígenas. En las estrategias de resistencia frente al empeoramiento de las condiciones socieconómicas desde el 2015 a partir de la interrupción del pago de programas sociales para Wawa wasi, la presencia de las mujeres en los reclamos en nombre de la comunidad y en defensa de su fuente laboral, recupera la noción de cuerpo-territorio.

Por último, el análisis de las ceremonias que organizan las actividades de la Asociación a partir del calendario ritual andino, ilumina el hecho de que estas prácticas dejan marcas en el espacio urbano que no son "patrimoniales" ni "monumentales", sino que se inscriben, a partir de la repetición calendárica, en determinados lugares en el espacio público, eventualmente considerados sagrados. Esto resulta relevante para pensar los lugares de memoria desde una realidad pluriétnica sistemáticamente negada en ciudades como La Plata.

Ciertamente, uno de los logros de esta tesis es que habilita la posibilidad de un ejercicio introspectivo por parte de quienes habitamos y compartimos este territorio urbano y el ámbito institucional universitario: ¿Qué horizontes abre la pregunta por la memoria indígena en la ciudad? ¿Cuál es el peso del imaginario fundacional de la ciudad de La Plata y su Universidad -creadas en pleno auge modernizador- sobre la definición de aquello que se estudia, sus métodos y enfoques? ¿Cómo y, sobre todo, por qué visibilizar las experiencias étnico-políticas y la presencia indígena en el espacio urbano?.

Finalmente, otra gran contribución de esta tesis que debe señalarse es dar cuenta de la agencia indígena desde una mirada interseccional que revela el papel de las mujeres en la construcción de la memoria colectiva y en los procesos de lucha y resistencia, desde una imaginación política nutrida de los feminismos decoloniales, indígenas y comunitarios.

\section{ReFERENCIAS}

Delrio,W., Lenton, D., Musanti, M, Nagy, M. Papazian, A y Pérez, P. (2010) "Del silencio al ruido en la Historia. Prácticas genocidas y pueblos originarios en la Argentina". III Seminario Internacional Políticas de la Memoria "Recordando a Walter Benjamin: Justicia, Historia y Verdad. Escrituras de la Memoria". Buenos Aires, Centro Cultural de la Memoria Haroldo Conti.

Lenton. D (2014) “Memorias y silencios en torno a la trayectoria de dirigentes indígenas en tiempos represivos", Revista TEFROS, 12 (2), 190-211. ISSN 1669-726X 